\title{
Competing interests of authors: We have revised our policy
}

$\mathrm{C}$ ompeting interests of authors can undermine the credibility of medical literature and, by extension, medical journals. Because the nature and importance of competing interests evolve, CMAJ has updated its policies. Here is what we have changed and why.

Editorial policies have traditionally focused on mandating disclosure of financial interests because those interests are the easiest to identify and measure. Our goal is to protect the integrity of the articles in our journal from many forms of external influences. Therefore, our revised policy takes a broad perspective on what constitutes a competing interest. Nonfinancial interests may exert equal or greater influence on authors' perspectives and the content of an article. Other editors seem to agree. In March 2009, the World Association of Medical Editors revised its policy on competing interests to emphasize nonfinancial competing interests, including academic commitments, personal relationships, political or religious beliefs and institutional affiliations. ${ }^{1}$

Most journals, including CMAJ, emphasize disclosure as the primary means of addressing competing interests. This rests on the honour system. Our revised policy builds on this foundation. It retains the major elements of our previous policy but broadens our requirements for disclosure in several areas.

First, when authors write on behalf of a group (e.g., a professional organization, advocacy group or institution), we now require disclosure of the authors' individual competing interests and of the competing interests of their group. For example, if a national specialty society publishes clinical practice guidelines, we expect the society to disclose any sponsors who contributed money to the society for the production of the guidelines. If the dean of a medical school writes an opinion piece expressing the perspective of his or her institution, he or she would be required to declare any relevant competing interests the medical school holds. On the other hand, the dean would not be required to disclose the institution's competing interests if he or she sought to publish a scientific research paper unrelated to his or her administrative role.

Second, we will no longer determine the eligibility for publication of articles such as commentaries or reviews based on a threshold dollar amount of an author's competing financial interests. Ex- plicit financial thresholds have the advantage of clarity and transparency, but they are arbitrary. What constitutes enough money to influence someone's perspective varies widely, making it impossible to agree on a universally valid amount. In contrast, evidence suggests that the nature of the relationship underlying any competing interest, rather than the amount of money involved, determines its influence. ${ }^{2}$ So we will consider and require disclosure of all competing interests, regardless of the amount. Our new policy aligns with the current understanding of the nature of competing interests, and it places responsibility for decisions about an author's eligibility squarely on the shoulders of the editors, where it belongs. In some instances, this policy will allow us to be stricter in our choice of authors than our previous policy permitted.

Third, although CMAJ has always published nonfinancial competing interests that authors disclosed voluntarily, we will now routinely request disclosure. Although such disclosures

\section{CMAJ's revised policy on competing interests}

1. All authors and contributors of all articles considered for publication in CMAJ must disclose any competing interests, financial or otherwise.

2. CMAJ will publish all relevant competing interests for all articles.

3. Competing interests held in the past must also be declared if they were held recently enough that, given their nature, a reasonable reader would consider them potentially influential.

a. At a minimum, the editors will consider relevant all competing interests held within 2 years of the date of manuscript submission.

b. This time will be measured from the date that funding ceased (e.g., the expiration date of a grant) or the relationship ended (e.g., termination date of a consulting contract).

4. Authors writing as representatives of an institution or organization must declare any relevant competing interests of their institution or organization as well as their own personal competing interests.

5. The editors' decision about eligibility of an article for publication will take into account the nature and amount of the competing interests and the context of the article. The decision will not be based solely on a specific threshold dollar amount.

6. Articles whose purpose is to offer an opinion or make recommendations, such as commentaries and narrative reviews, including commissioned articles, may be excluded from publication if any author has a competing interest that, in the editors' opinion, would be likely to detract substantially from the credibility of the article.

a. Competing interests that would usually exclude an author from publication include financial investments such as equity, shares, derivatives and bonds (excluding publicly traded mutual funds), royalties or patents (current or pending) related to a company that markets a product (or competes with another company's product) mentioned in the article.

b. Employment by, contractual relationships of any type with, or being a named officer or board member of such companies would usually exclude an author from publication.

c. These exclusions might be waived under special circumstances (e.g., if the point of view of a company is specifically desired). 
are harder to enforce and verify, we believe that our policy should match our concept of the breadth of potential influences on articles.

Full disclosure is particularly important for authors of commentaries, editorials and review articles. Because such articles often offer explicit guidance, readers expect a stronger guarantee of integrity.

CMAJ is committed to managing the competing interests of authors in a fair and transparent manner. Consensus of at least 2 editors is required to decide about an author's eligibility to publish commentaries or review articles when competing interests exist. We are open to hearing appeals from authors who feel that we have erred in our judgment.

Our new policy enhances our ability to ensure the integrity of articles published in CMAJ. Editorial policies alone are not sufficient to do this. Successful management of competing interests requires the support of all stakeholders. Other stakeholders, such as academic institutions, also have a responsibility to ensure that they put processes in place to require the disclosure of competing interests. Moreover, scrutiny by peers must enforce the honour system that requires authors to disclose everything relevant to their publication. CMAJ con- tinues to welcome the opportunity to update and correct the scientific record when readers identify omissions of competing interest declarations.

Competing interests, and the editorial policies that respond to them, will continue to evolve. As always, we welcome feedback from our readers on how we are doing.

Matthew B. Stanbrook MD PhD, Ken Flegel MDCM MSc, Noni MacDonald MD MSc, Amir Attaran LLB DPhil, Laura Eggertson BA, Barbara Sibbald BJ, Diane Kelsall MD MEd, John Fletcher MB BChir MPH, Joan Ramsay BA, Rajendra Kale MD, and Paul C. Hébert MD MHSc

Competing interests: See www.cmaj.ca/misc/edboard.shtml

\section{REFERENCES}

1. Editorial Policy and Publication Ethics Committees. Conflict of interest in peer-reviewer medical journals. Shiraz (Iran): World Association of Medical Editor (WAME); 2009. Available: www.wame.org/conflict-of-interest-in-peer-reviewedmedical-journals (accessed 2009 June 1).

2. Dana J, Loewenstein G. A social science perspective of gifts to physicians from industry. JAMA 2003;290:252-5. 